\title{
REVISTAMARACANAN
}

Dossiê

\section{O general do Norte: Juarez Távora e o movimento pelo seu generalato no imediato pós-1930}

\section{The general of the North: Juarez Távora and the movement in favor of the generalate in the immediate post-1930}

Recebido em: 8 set. 2020.

Aprovado em: 30 nov. 2020.

Raimundo Helio Lopes*

Instituto Federal de Educação, Ciência e

Tecnologia Fluminense

Campos dos Goytacazes, Rio de Janeiro, Brasil

\footnotetext{
* Professor do Instituto Federal de Educação, Ciência e Tecnologia Fluminense, Campos dos Goytacazes. Doutor em História, Política e Bens Culturais no Centro de Pesquisa e Documentação de História Contemporânea do Brasil da Fundação Getúlio Vargas; Mestre e graduado em História pela Universidade Federal do Ceará. E-mail: raimundohelio@gmail.com

(iD) https://orcid.org/0000-0002-1581-7035 (6) http://lattes.cnpq.br/8217029095390746
} 


\title{
Resumo
}

O artigo analisa o movimento pelo generalato de Juarez Távora no imediato pós-1930. Por sua ação na tomada de poder, Távora era um destacado herói nacional, o que possibilitou a força dessa iniciativa, organizada por civis e militares do "Norte", região geopolítica que Távora liderava. Tendo como fontes centrais de análise a documentação do arquivo pessoal de Juarez Távora e a imprensa da região Norte, é possível analisar como esse movimento foi amplo e fundamental para definir as estratégias do grupo que formava essa região. O generalato não foi efetivado, mas esse movimento deixa antever muitos aspectos para se entender a Revolução de 1930 e os primeiros momentos do Governo Provisório.

Palavras-chave: Juarez Távora. Região Norte. Imediato pós-1930. Generalato. Governo Provisório.

\begin{abstract}
The article analyzes the movement in favor of the promotion to general of Juarez Távora in the immediate post-1930s. For his action in the seizure of power, Távora was a prominent national hero, which enabled the strength of this initiative, organized by civilians and military personnel from the "North", a geopolitical region that Távora led. From the documentation of the personal archive of Juarez Távora and the press in the North, central sources of analysis, it is possible to analyze how this movement was broad and fundamental to define the strategies of the group that formed this region. The generalate was not made effective, but this movement allows the compreension of many aspects that are essential to understand the Revolution of 1930 and the first moments of the Provisional Government.
\end{abstract}

Keywords: Juarez Távora. North Region. Immediate post-30. Generalate. Provisional Government. 
Entre os dias 24 de junho e 30 de agosto de 1946, Juarez Távora recebeu mais de mil correspondências tratando de um único tema: sua promoção a General-de-Brigada do Exército Brasileiro. Entre essas muitas cartas, bilhetes e telegramas, pelo menos uma dezena o parabenizava lembrando outros tempos: "receba grande abraço pela promoção tardiamente confirmada aclamação popular 1930 e seu patriotismo escrúpulo recusou". ${ }^{1}$

A memória do imediato pós-30 foi mobilizada por muitos admiradores e amigos de Juarez Távora, fazendo antever que naquele momento o generalato fora uma possibilidade não concretizada, mas que agora, muitos anos depois, se confirmava. Dentre os vários correspondentes de Távora, alguns eram ilustres militares que também evocavam aqueles dias:

Rio, 24 junho 1946

Meu caro Juarez,

Com o prazer de referendar o decreto de promoção do general já aclamado pelo Norte, há mais de 15 anos, eu lhe envio e à D. Nair, com a Conceição e meus filhos, nossos abraços de efusivas felicitações pelas boas festas joaninas. [...] P. Góis. $^{2}$

Pedro Aurélio de Góis Monteiro, grande líder do Exército Brasileiro desde 1930, foi articulador do golpe do Estado Novo e da deposição de Getúlio Vargas em 1945 e alcançara o generalato no mesmo contexto no qual a promoção para Juarez não foi efetivada. Góis Monteiro, alagoano, escrevia a Juarez Távora, cearense, em tom de cordialidade, mostrando proximidade entre as famílias e brincando com o dia de São João. Em 1946, a "invenção do Nordeste" estava em pleno curso, e aspectos culturais, como as festas populares, foram elementos mobilizados na construção dessa região. ${ }^{3}$

Mas, ainda nessa carta, uma outra região aparece e não pode ser minimizada: o Norte. Ou melhor, um Norte específico, historicamente situado, que aclamou Távora como general em um movimento que, apesar de não ter conseguido seu objetivo principal, ainda estava na memória de muitos daqueles que o viram. Por essas correspondências, um personagem e um contexto se revelam fundamentais para o entendimento desse Norte: Juarez Távora e o imediato pós-30.

Juarez do Nascimento Fernandes Távora tornou-se uma figura de renome nacional desde quando atuara nas revoltas tenentistas da década de 1920. Depois de lutar em São Paulo, em 1924, tornou-se um dos líderes da Coluna Prestes que marchara por milhares de quilômetros questionando a Primeira República. Ele ainda era um jovem militar rebelde em outubro de 1930 quando, aos 32 anos, foi o principal articulador do movimento armado que

\footnotetext{
${ }^{1}$ FUNDAÇÃO GETÚLIO VARGAS - RIO DE JANEIRO (FGV-RJ). Centro de Pesquisa e Documentação de História Contemporânea do Brasil (CPDOC), Arquivo Juarez Távora, dpf 1946.06.24 (68/1063). Telegrama assinado por Evardo Backhevser.

${ }^{2}$ Ibidem, (19/1063).

3 Cf.: ALBUQUERQUe JÚNIOR, Durval Muniz de. A invenção do nordeste e outras artes. São Paulo: Cortez, 2009.
} 
derrubou os governos dos chamados estados "setentrionais" do país. Com a vitória, Juarez Távora passou a ter enorme liderança e prestígio junto àqueles que apoiavam o movimento de 30 nos estados que hoje compreendem as atuais regiões Norte e Nordeste, e a partir da sua ligação com esses sujeitos começou a ser formado o Norte surgido no imediato pós-30.

Entendo por imediato pós-30 o período de enorme instabilidade política que vai da vitória da Revolução de 30 até a guerra civil de 1932, caracterizado por embates acerca, sobretudo, da reconstitucionalização do país, no qual muitos grupos se aproximaram e se afastaram do Governo Provisório. Nessa conjuntura, diversos projetos de poder surgiram, concorrendo ou se fundindo com aquele que estava sendo esboçado pelas principais lideranças civis e militares que comandavam o Governo Provisório. É nessa arena de disputas que surge o Norte que trata esse artigo.

Este Norte é uma construção histórica e não um dado da realidade que existe por si só. Ele só é compreensível e delimitado a partir de determinados parâmetros e da ação de uma série de sujeitos. Em primeiro lugar é importante dizer que a palavra norte, como ideia de uma ordenação espacial nacional do país já existia desde antes de 1930, pelo menos desde o século XIX, e ao longo do tempo teve seus significados e fronteiras alterados a partir de interesses e conflitos.

Em segundo lugar, o Norte surgido no imediato pós-30 é historicamente situado no tempo e no espaço: teve seu início com a derrocada da Primeira República e seu fim com o processo constitucional de 1934, quando seus artífices e lideranças abriram mão desse Norte como objeto de significância na luta política que travavam. Espacialmente ele era formado pelo território federal do Acre e pelos estados do Amazonas até o Espírito Santo. Eram 13 unidades federativas que foram se aglutinando enquanto grupo ao longo do Governo Provisório, passando por variações e momentos de maior ou menor coesão. O Espírito Santo é emblemático nesse sentido: nos primeiros meses após a vitória do movimento de 30 não aparece como um estado nortista, mas quando a crise política que culmina na Guerra de 1932 torna-se imensamente forte, o estado capixaba passa a compor com esse grupo político e "entra" nesse Norte liderado por Juarez Távora. O processo político que leva à guerra civil é, por sinal, o momento no qual a região está mais forte e melhor delimitada, tornando-se o principal aliado de Getúlio Vargas na luta contra aqueles que tentaram derrubar seu governo com armas na mão. Esse apoio pode ser percebido não só no envio de milhares de soldados regulares e voluntários - mas também no destacado papel que os interventores do Norte tiveram em seus estados.

Em terceiro lugar, a formação dessa região só é possível de ser percebida no seu processo de construção e a partir da ação dos sujeitos que assim a constituíram, com aproximações, conflitos, apropriações e (inter)relações, internas e externas à própria configuração regional que estavam estabelecendo. Não só aqueles que reconheciam a liderança de Távora enxergavam o Norte que surgiu depois da derrubada da Primeira República. Os opositores a essa corrente política se apropriaram da ideia dessa região para 
confrontá-la, utilizando-se da categoria irônica e pejorativa de "Vice-Reinado do Norte", que buscava desqualificar e questionar o papel de Távora e seus liderados. As apropriações da região, por aliados e opositores, evidenciam a necessidade de entendê-la com complexidade, como ensina Albuquerque Júnior:

\begin{abstract}
Falar em região é se referir àqueles que foram derrotados em seu processo de implantação, àqueles que foram excluídos de seus limites territoriais ou simbólicos, àqueles que não fazem parte dos projetos que deram origem a dado recorte regional. Falar de região implica em reconhecer fronteiras, em fazer parte do jogo que define o dentro e o fora: implica em jogar o jogo do pertencimento e do não pertencimento. Fazer história da região é cartografar as linhas de força, o diagrama de poderes que conformam, sustentam, movimentam e dão sentido a um dado recorte regional. ${ }^{4}$
\end{abstract}

Depois da tomada de poder, os principais apoiadores de Távora passaram a ocupar os mais importantes postos de comandos estaduais no Norte, como - mas não exclusivamente as interventorias, por sua indicação direta ao presidente da República. Durante todo o Governo Provisório, praticamente todos os interventores dos estados do Norte foram indicados diretamente por Juarez Távora. A documentação pessoal de Távora e dos revolucionários nortistas é rica em mostrar as ligações específicas entre esse grupo, assim como sua formação e atuação. É principalmente nesse conjunto documental, assim como na imprensa da época, que é possível encontrar, delimitar e estabelecer as especificidades dessa região. Como mostra Cláudia Viscardi, "o espaço regional consiste em uma construção abstrata, elaborada no decorrer do tempo por atores coletivos que a ele se relacionam direta ou indiretamente. É formado por um conjunto de valores socialmente aceitos e partilhados pelos seus agentes, que conferem à região uma identidade própria, capaz de gerar comportamentos mobilizadores de defesa de interesses". ${ }^{5}$

Nesse sentido, um dos elementos determinantes para a formação da identidade do Norte nesse contexto é como os sujeitos que integravam e formavam essa região se autodefiniam: "revolucionários nortistas". Eles acreditavam que a revolução só teria cumprindo seu papel quando o Norte que lideravam estivesse recuperado das práticas políticas que vigoraram durante a Primeira República, assim como, em um duplo movimento, a região que estavam construindo tivesse lugar de destaque junto ao governo federal na nova configuração política nacional. ${ }^{6}$

Para tanto, em 12 de dezembro de 1930, Juarez Távora, depois de recusar o ministério da Viação e Obras Públicas e indicar para tal José Américo de Almeida, foi nomeado por Getúlio Vargas Delegado Militar do Governo Provisório no Norte, órgão subordinado ao ministério da Guerra, suis generis na estrutura governamental e bastante esquecido quando se pensa, hoje,

\footnotetext{
${ }^{4}$ ALBUQUERQUE JÚNIOR, Durval Muniz de. O objeto em fuga: algumas reflexões em torno do conceito de região. Fronteiras, Dourados (MS), v. 10, jan.-jun. 2008, p. 58.

${ }^{5}$ VISCARDI, Cláudia Maria Ribeiro. História, Região e Poder: a busca de interfaces metodológicas. Locus: revista de história, Juiz de Fora MG), v. 3, n. 1, 1997, p. 95-96.

${ }^{6}$ LOPES, Raimundo Helio. Um Vice-reinado na República do pós-30: Juarez Távora, as interventorias do Norte e a Guerra de 1932. 2014. Tese (Doutorado em História, Políticas e Bens Culturais) - Centro de Pesquisa e Documentação de História Contemporânea do Brasil, Fundação Getúlio Vargas, Rio de Janeiro, p. 38-45.
} 
os primeiros anos do Governo Provisório. ${ }^{7}$ Desde os primeiros momentos do Governo Provisório, Távora deixara claro tanto para seus aliados quanto para seus adversários qual papel queria assumir. Em primeiro lugar, liderar a reestruturação política, militar e administrativa do Norte junto com os seus interventores, que ele mesmo indicava ao presidente para serem nomeados. Em segundo, anunciava que era no Exército, e não em cargos civis, que passaria a atuar, por mais que sua ação tenha se expandido bem mais do que o âmbito militar.

Esse Norte aqui analisado a partir da busca pelo generalato de Juarez Távora já não existe mais, apesar de ter tido considerável força política. Na construção da memória e da história sobre o turbulento período entendido como Governo Provisório ele praticamente desapareceu ou, quando muito, aparece justamente como aquilo que nunca foi: algo estático, a-histórico e superficial. Por mais que possua "relações internas autônomas que lhe conferem caráter próprio e diferenciado", o Norte surgido no imediato pós-30, com suas relações com o "sistema maior" da política nacional, "faz parte da totalidade social; portanto, suas características internas são determinadas e determinantes de sua interação com o todo". ${ }^{8}$

Por isso, recuperar eventos marcantes que foram fundamentais para a constituição desse Norte pouco observado em sua complexidade é dar outros entendimentos para os primeiros anos de Getúlio Vargas no poder, contribuição determinante que uma abordagem regional da história pode trazer. A luta pelo generalato do Juarez coloca luz, a partir de novos ângulos, em um dos momentos mais conturbados de toda a história republicana brasileira.

\section{O general proclamado em plena rua}

Juraci Magalhães - um dos principais nomes entre os revolucionários nortistas, por chefiar a brigada leste do movimento armado que derrubou a Primeira República no Norte escreveu a Juarez Távora, em 23 de dezembro de 1930, na qualidade de um dos chefes do $22^{\circ}$ Batalhão de Caçadores, da Paraíba. Em um documento revelador do momento confuso e incerto - mas também estratégico e cheio de possibilidades -, Juraci comenta:

Acho, meu caro Juarez, que de prático nada ainda realizamos em favor das
massas sofredoras. Tudo ficou em promessas. [...] Os sinceros são uma minoria
e estes sinceros exigem que superponha à tua modéstia o interesse nacional. Se
não tiveres uma situação de realce material - pois moral tens de sobra - dentro
do Exército, a revolução fracassará em sua finalidade, o que será doloroso para
a memória dos nossos mártires e desprimoroso para os que tiveram alguma

\footnotetext{
7 "Mesmo que as categorias de Vice-Rei e Vice-Reinado tenham permanecido - e ainda permaneçam mais fortes e frequentes do que Delegacia do Norte e revolucionários nortistas na bibliografia corrente que trata do Governo Provisório, elas não são sinônimas e nem se limitam ao ato de nomear interventores. São categorias diferentes, que revelam processos distintos e complexos, mas que se completam para entender o Norte constituído no imediato pós-1930, assim como a própria trajetória política de Juarez". LOPES, Raimundo Helio. O Vice-Rei do Norte: Juarez Távora entre inimigos e aliados. Revista Tempo, IH/UFF, v. 23, 2017, p. 152.

8 RECKZIEGEL, Ana Luiza Setti. História regional: dimensões teórico-conceituais. História - debates e tendências, Passo Fundo (PR), v. 1, n. 1, p. 15-22, 1999, p. 19.
} 
parcela de responsabilidade para o movimento. Julgo que não tens o direito de sacrificar a $2^{a}$ república como Benjamin Constant sacrificou a $1^{a}$, por uma modéstia descabida. ${ }^{9}$

A carta é claramente uma advertência: se Juarez Távora não agisse seria derrotado, e precisava ganhar uma posição de "realce material" dentro do Exército, para se sobrepor às outras correntes políticas que agiam naquele momento. Não poderia fugir a esse dever, não tinha o direito à "modéstia", aspecto que Juraci cita mais de uma vez. Juarez precisava defender o "interesse nacional", pois o tempo traria o esquecimento se ele não ocupar o lugar de destaque "que merece". Não poderia ser o Benjamim Constant da Segunda República: militar, grande líder positivista que conspira e articula a proclamação, mas que se torna uma figura secundária rapidamente. Essa comparação feita por Juraci é interessante para mostrar como, para os revolucionários nortistas, a Revolução de 30 inaugurava uma nova república e que havia precedentes para o fim do "prestígio incontestável" que um líder possuía em momentos como este. Nesse sentido, a "modéstia" atribuída a Juarez é, claramente, um eufemismo para falta de ousadia política.

Juraci Magalhães apresenta a ação necessária para a consolidação efetiva da liderança nacional de Juarez: "Faz-se mister que teu generalato seja uma garantia para o cumprimento do programa revolucionário, pois precisa ter a força material para poder exigir a execução do que prometemos ao povo". Só como general Juarez conseguiria poder para conseguir o cumprimento dos ideais definidos pelos revolucionários nortistas, pois eles "não precisam ver estrelas e bordados para atenderem a um aceno teu, mas é incontestável que teu prestígio será muito maior para o povo se fores general de direito como o é de fato". A articulação, segundo ele, tinha força: "falei com o Dr. Osvaldo Aranha que prometeu fazer a promoção, mesmo a tua revelia." Ele já comentara com um dos mais importantes líderes civis Revolução de 30 e então ministro da Justiça sobre a nomeação, e deixa antever que ele também concordava com a promoção, pois nomearia Távora mesmo sem seu aceite. A promoção era necessária, e se não viesse por via de procedimentos oficiais, viria, como forma de pressão, fora desses parâmetros. Juarez Távora seria proclamado general pelo povo, nas ruas, revolucionariamente: "Passados 20 dias de tua chegada ao Rio, se nada houver nesse sentido serás proclamado general do Exército pelo povo e classes armadas do Norte, em plena rua". ${ }^{10}$

Caso o projeto exposto por Juraci Magalhães se confirmasse, seria uma escalada militar meteórica, nunca antes vista: de capitão, Juarez Távora pularia os postos superiores de major, tenente-coronel e coronel, chegando ao de general-de-brigada, posto inferior apenas aos de general-de-divisão e marechal.

Em outra carta, Juraci volta a escrever para tratar do generalato. Seu tom continua pessimista - "nossos 'amigos' (?) estão minando teu prestígio junto à opinião pública nacional" - e agressivo - "esses imbecis não veem que o teu é o único nome capaz de por um dique à propaganda moscovita, que vai aumentando dia a dia". Além das disputas internas entre os

${ }^{9}$ FGV-RJ. CPDOC, Arquivo Juarez Távora, dpf 1930.12 .08 (64-74/7455).

${ }^{10}$ Ibidem, (64-74/7455). 
vencedores da Revolução de 30, a apatia de Távora em elevar-se general trazia outro grave problema: contribuía para a ascensão do comunismo: "o nome de Prestes já voltou a ter aquela auréola que a nossa propaganda criou em torno dele e o seu espírito esclarecido vai tirando partido para desenvolver o ódio da massa contra o governo e seus prepostos." A relação que faz com Luís Carlos Prestes não é fortuita. Apenas a liderança de Juarez - que esteve ao lado de Prestes na década de 1920, ou seja, tinham um passado de lutas em comum - seria mais forte do que a do antigo aliado, pois este levara seu enorme prestígio para a corrente comunista, contribuindo bastante para seu crescimento. ${ }^{11}$ Ao final, reafirmava que a causa disso tudo era, novamente, "a tua modéstia de permanecer um simples capitão, afastado do poder, quando deverias ser o executor desse programa que nos levou a tantos sacrifícios." Feito general, Juraci acreditava que Távora conseguiria mais força para melhor liderar os revolucionários nortistas, pois teria "um Estado Maior" para melhor remeter "as ordens vindas para o Norte". Ou seja, Juraci argumenta que o generalato não concorria com a liderança que exercia na região, mas, ao contrário, a fortaleceria: "mais um motivo é assim para o teu generalato, que sairá breve". ${ }^{12}$

A ideia parece arrojada e extrema. Mas estava dentro da conjuntura militar e política que se iniciara com a derrubada da Primeira República, pois, desde então, o Exército passava por significativas mudanças, tendo sido protagonista de muitos movimentos militares e políticos, favoráveis ou contrários ao governo nos anos que seguiram. As forças armadas estavam no centro do poder de modo bem mais decisivo do que ocorrera após a proclamação da República. Mas, justo por isso, o Exército, como instituição, viu-se envolvido em fortes choques de correntes antagônicas. Com uma organização fragmentada, houve dificuldades para se estabelecer uma nova hierarquia de comando, o que também se via nas disputas para a montagem da nova cúpula de poder. A promoção de oficiais superiores, antes de 1930, era marcada por uma relação de apadrinhamento, sendo um poderoso instrumento nas mãos do presidente da República para punir seus opositores ou premiar seus aliados. Assim, no imediato pós-30, quebrou-se "o antigo esquema de lealdade que prendia os generais aos presidentes", sendo necessária "a criação de novas lideranças hierárquicas". Com isso, "uma das principais preocupações dos vencedores de 1930 foi criar essas lideranças" e "a maneira de o fazer era promover a rápida substituição da cúpula militar do velho regime". ${ }^{13}$

Nesse processo, os números impressionam: no início de 1931, constavam entre aqueles que foram reformados quinze marechais, oitenta generais-de-divisão, 324 generais-debrigada, 102 coronéis, 126 tenentes-coronéis, 363 majores, 323 capitães, 191 primeiros-

${ }^{11}$ Cf.: MOTTA, Rodrigo Patto Sá. Batalhas em torno do mito: Luiz Carlos Prestes. Estudos Históricos, Rio de Janeiro, n. 34, 2004.

${ }_{12}$ FGV-RJ. CPDOC, Arquivo Juarez Távora, dpf 1930.12.08, (118-124/7455). Datada de 7 de janeiro de 1931.

${ }^{13}$ CARVALHO, José Murilo de. Forças Armadas e política no Brasil. São Paulo: Todavia, 2019, p. 95-97, 101. 
tenentes e 581 segundos-tenentes. ${ }^{14}$ Foi nesse ambiente de total reestruturação militar que muitos dos apoiadores de Juarez Távora viram a possibilidade concreta dele tornar-se general do Exército Brasileiro.

Como anunciou o futuro interventor da Bahia, as iniciativas pelo generalato de Juarez Távora iam para além dos círculos militares e angariou força através de um movimento em todo o Norte. Analisar com vagar, mas de modo denso, o desenrolar desse movimento revela o "horizonte de expectativa" aberto com a Revolução de 30, marcado por conflitos e projetos pouco observados, mas fundamentais para entender o "espaço de experiência" que permitiu a consolidação de algumas lideranças e apagamento de outras. ${ }^{15}$

As primeiras notícias sobre o movimento pelo generalato de Juarez Távora aparecem na imprensa do Norte no dia 9 de janeiro de 1931, em Pernambuco. Esse evento seria um "formidável" e "grande plebiscito popular" no qual Juarez Távora seria "aclamado" general-debrigada. Sem nenhuma menção a ação de militares como Juraci Magalhães, a iniciativa partira de "uma comissão de pernambucanos composta pelo sr. Caio de Lima Cavalcanti e drs Mário de Castro e Orlando Aguiar", ou seja, civis. "Interpretando o sentir geral do povo", os organizadores do movimento solicitavam a Vargas "a merecida promoção do capitão Juarez Távora ao posto de general-de-brigada". Para tanto, não faltavam qualidades ao seu líder. Segundo a comissão, em telegrama a todos os interventores da região, Juarez era "hoje [um dos] maiores símbolos [das] reinvindicações nacionais", já que "por amor ideal revolucionário sofreu exílio, perseguição tenaz", mas esse "sacrifício" e "dignidade" visavam sempre o "engrandecimento [da] pátria." Távora era o "comandante [dos] exércitos libertadores", com "êxito fulminante [nas] marchas [de] operações", sendo sua "aclamação posto general brigada" um "ato [de] justiça". ${ }^{16}$ Envolvendo lideranças civis, militares e interventores, esse movimento em torno do "plebiscito popular" revela que a advertência feita por Juraci era verdadeira, ganhou força e, ao menos na voz de seus articuladores, construía-se como popular.

No entanto, antes do dia marcado para a realização do ato pró-generalato, Juarez Távora escreveu a todos os interventores nortistas desautorizando o movimento. Justificava sua discórdia dizendo que maior atenção deveria ser dada à solução dos problemas que "interessam [à] coletividade" e que se sentia "bem vestindo farda capitão". "Considero de justiça só ascender outros postos através exigências normais leis de promoção que governo república vir decretar beneficiando toda minha classe e não apenas alguns indivíduos", ${ }^{17}$ finalizou taxativo. Em suas palavras, a "modéstia" que seus aliados percebiam ficava mais evidente. Seu recuo tentou jogar água fria na fervura dos revolucionários nortistas pelo seu

\footnotetext{
14 MCCANN, Frank D. Soldados da Pátria: história do exército brasileiro, 1889-1937. São Paulo: Companhia das Letras, 2007, p. 393.

${ }^{15}$ KOSELLECK, Reinhart. Futuro Passado: contribuição à semântica dos tempos históricos. Rio de Janeiro: Contraponto; Ed. PUC-Rio, 2006, p. 305-327.

${ }_{16}$ Juarez Távora, general da vitória e do Exército Brasileiro - O formidável plebiscito do dia 14 em todo o norte do Brasil, da Bahia ao Amazonas. Jornal Pequeno, Recife, 9 jan. 1931, p. 1.

${ }^{17}$ FGV-RJ. CPDOC, Arquivo Juarez Távora, dpf 1930.12.30 (3-4/116). Datado de 10 de janeiro de 1931.
} 
generalato, mas pouco adiantou. O interventor do Rio Grande do Norte respondeu-Ihe questionando: "o Norte, vendo a bravura de Osvaldo Aranha e Miguel Costa premiada com bordados generalato, não podia deixar desejar posto maior destaque aquele que [...] não foi ultrapassado no Brasil". ${ }^{18}$ Irineu Joffily estava correto, pois Miguel Costa recebeu "honras do posto de general-de-brigada" devido "aos relevantes serviços prestados", ${ }^{19}$ e Osvaldo Aranha ganhou o título de "general honorário do Exército", ambos por atos do Governo Provisório. ${ }^{20}$

A comissão geral pelo generalato telegrafou às congêneres nos demais estados nortistas refutando Juarez Távora. Para ela, "este movimento [é] espontâneo [entre a] opinião pública, não prêmio serviços transitórios" e que o "posto [de general é] indispensável [na] consolidação [da] obra revolucionária". Além disso, reafirmava: Juarez "não pertence a si" mas ao "Brasil inteiro que reclama serviços ininterruptos seu patriotismo e nobre espírito sacrifício pátria." Por isso mesmo, seu comunicado desautorizando essa iniciativa teve pouco efeito prático: "prosseguiremos preparativos plebiscito". ${ }^{21}$

No dia marcado, a aclamação pelo generalato aconteceu com força e amplitude em todo o Norte. Milhares de pessoas mobilizaram-se não só nas capitais dos estados mas também em pequenas e médias cidades nortistas: foram registradas manifestações públicas em Cabrobó $(P E)$, Araruna (PB), Sobral (CE), Capela (SE), Penedo ( $A L)$ e Sena Madureira (AC) ${ }^{22}$ A maneira como ele se desenrolou em Recife - onde apareceram as primeiras notícias públicas sobre o movimento pelo generalato - é um ótimo parâmetro para entender sua força e seus significados em toda a região.

A lista de "patrocinadores" em Pernambuco contava com oito jornais, o Círculo Católico, membros da Faculdade de Direito e Medicina, escolas de Engenharia, Normal e Ginásio Pernambucano, Jockey Club, Maçonaria, diversas associações de classe, operários e estudantes. ${ }^{23}$ Uma sessão do Instituto Arqueológico e um leilão de açúcar nas docas que ocorreriam no dia do movimento tiveram que ser adiados. ${ }^{24}$ A Associação dos Empregados do Comércio de Pernambuco e a Associação Comercial, por solidariedade, encerraram seu expediente ao meio-dia, mesma medida adotada pelo interventor para as repartições públicas. $^{25}$

Às 4 horas da tarde, na praça Barão de Lucena, no centro da cidade, teve início a "imponente cerimônia cívica". Nela as bandas de música do 21.0 Batalhão de Caçadores, da

\footnotetext{
${ }^{18}$ FGV-RJ. CPDOC, Arquivo Juarez Távora, dpf 1930.12.30 (10/116). Datado de 13 de janeiro de 1931.

${ }_{19}$ Importantes decretos na pasta da Guerra. Correio da Manhã, Rio de Janeiro, 9 nov. 1930, p. 2.

20 Uma expressiva homenagem dos colegas de turma do senhor Osvaldo Aranha. Correio da Manhã, Rio de Janeiro, 28 dez. 1930, p. 3.

${ }^{21} \mathrm{O}$ grande movimento do Norte pleiteando o generalato para Juarez Távora. Jornal Pequeno, Recife, 13 jan. 1931, p. 3.

22 Ver jornal Correio da Manhã, Rio de Janeiro, dias 11, 13, 14 e 15 jan. 1931. As imprensas pernambucana e cearense também noticiaram esse movimento em várias outras cidades do Norte.

23 Juarez Távora. Diário de Pernambuco, Recife, 10 jan. 1931, p. 1.

24 Instituto Arqueológico. Diário de Pernambuco, Recife, 13 jan. 1931, p. 4; Aviso! Diário de Pernambuco, Recife, 13 jan. 1931 , p. 7.

${ }^{25}$ Novo general. Jornal do Recife, Recife, 14 jan. 1931, p. 1; Juarez Távora - o grande plebiscito que se realizará hoje em todo o norte do país em prol do generalato para o bravo soldado republicano. Diário de Pernambuco, Recife, 14 jan. 1931, p. 3.
} 
Brigada Militar e da União Operária tocaram para uma "grande massa popular". ${ }^{26} \mathrm{O}$ ato redimia uma "dívida sagrada para com Juarez, o soldado incomparável, o estadista moço e esclarecido, o patriota inexcedível, o idealista magnânimo de fé ardentíssima nos gloriosos destinos do Brasil". Os articuladores lembravam ao povo que "os ódios se extinguem, as paixões se dissolvem, ao calor do ideal de uma pátria redimida, forte, feliz e unida" conforme os "ensinamentos do Evangelho cívico de Juarez". ${ }^{27}$ Oradores inflamados falavam que "nada Ihe falta em técnica militar, que as escolas de guerra não podem instruir a um cabo de guerra da sua extirpe" e que "se não o fizer [o generalato]" o Governo Provisório "não é governo revolucionário do Brasil". ${ }^{28}$

A leitura de dois telegramas foi o grande momento da mobilização. O primeiro foi endereçado ao presidente comunicando "a aclamação, na praça pública, do nome do libertador do Norte", dizendo que não foram apenas a "dedicação patriótica" e a "tenacidade [de] sacrifício" de Távora que motivaram o movimento, mas sim por ser ele um "grande soldado" com "ideal revolucionário com relevantíssimos serviços prestados" no Norte "graças ao seu gênio guerreiro" com "lances [de] verdadeiro heroísmo" contra a "opressão [das] oligarquias". O segundo, relatava ao próprio Juarez a "sagração popular do seu generalato". Diziam os liderados a seu líder que "elevação aquele posto não é prêmio que aliás bem merecerias, mas necessidade imperiosa pois que com mais ampla ação comando melhor podereis contribuir consolidação obra revolucionária". ${ }^{29}$

Por fim, mas não menos importante, vale atentar para a data na qual se realizou o movimento. Era o dia 14 de janeiro de 1931, quando Juarez comemorava seu aniversário de 33 anos, e casava-se com sua prima Nair Távora. ${ }^{30}$ A escolha da data não foi fortuita, pois seu casamento foi marcado por forte simbologia: entre os convidados, reuniu-se ao redor da família Távora a alta cúpula civil e militar do Governo Provisório, como os ministros Osvaldo Aranha, José Américo de Almeida e general Leite de Castro, e o próprio presidente Getúlio Vargas. Leite de Castro, o ministro da Guerra, inclusive fora um dos padrinhos. Seu matrimônio foi um ato político que simbolizou seu retorno à vida pública e uma forma "eficaz para reconstruir e tornar pública uma aliança" com a elite política e militar nacional, demonstrando que o "antigo guerreiro, então disposto a se instalar na vida e começar uma obra construtiva, gozava para tal da confiança de todos que tinham autoridade na época". ${ }^{31}$

\footnotetext{
${ }^{26}$ Juarez Távora, general da vitória e do Exército Brasileiro - A imponente cerimônia cívica de ontem. Jornal Pequeno, Recife, 15 jan. 1931, p. 1.

27 Juarez Távora, general da vitória e do Exército Brasileiro - O grande plebiscito de hoje, na Praça Barão de Lucena. Jornal Pequeno, Recife, 14 jan. 1931, p. 1.

28 Juarez Távora. Jornal do Recife, Recife, 15 jan. 1931, p. 1.

29 Juarez Távora - o grande comício popular de ontem em prol da elevação do intrépido chefe revolucionário do norte ao generalato do exército nacional. Diário de Pernambuco, Recife, 15 jan. 1931 , p. 3.

30 Ver: TÁVORA, Juarez. Uma vida e muitas lutas - memórias. Vol. 2: A caminhada no Altiplano. Rio de Janeiro: Biblioteca do Exército, 1976, p. 23-25.

${ }^{1}$ GARCIA JÚNIOR, Afrânio. Os Vice-Reis do Norte: reconversão de elites agrárias e a revolução de 1930 (1920-1964). Revista de Ciências Sociais, Fortaleza, v. 38, n. 2, 2007, p. 83.
} 
A "narrativa densa" do movimento pró-generalato de Juarez Távora aqui proposta busca revelar estruturas, conflitos e modos de pensar do imediato pós-30. ${ }^{32} \mathrm{Em}$ primeiro lugar, é importante perceber que os revolucionários nortistas mobilizaram dezenas de cidades de modo simultâneo em manifestações públicas para atropelar as normas militares e pressionar o presidente pela concessão da promoção de Juarez Távora. Se outras lideranças receberam o título de general de modo honorário, o que se buscava para o líder nortista era algo sem precedentes, posto sua rápida subida na hierarquia militar, através de uma iniciativa ampla, arrojada e arquitetada. Na correspondência privada, o movimento pelo generalato é descrito como politicamente fundamental para o Norte, mas também relevante para a reformulação do Exército Nacional. Para os revolucionários nortistas, a força da liderança de Juarez junto ao Norte dialogava com as incertezas nacionais que tanto preocupavam, como ele próprio argumentou quando procurou arrefecer a mobilização por seu generalato. Na argumentação desses sujeitos, quanto mais forte Juarez, mais forte seria a revolução e sua obra. $E$, mais fundamental ainda, a região que encarnavam em suas identidades políticas ganharia uma força política e militar determinante. Na imprensa, no entanto, o movimento era apresentado como espontâneo, popular, sem nenhum caráter político, apenas uma demonstração de gratidão pela ação de Juarez. Esse discurso público que naturalizava a iniciativa buscava neutralizar qualquer impedimento ou reação por parte de outras forças políticas que o vissem como uma insubordinação ou desrespeito ao poder recém-estabelecido, podendo ser encarado, inclusive, como uma ameaça ao próprio presidente. Esses dois discursos público e privado se complementam: mostram que o movimento pelo generalato era forte, articulado e não recuaria, sendo uma garantia para que a corrente liderada por Juarez não soçobrasse naquele conturbado momento político e militar, ancorada no elevado posto que Juarez passaria a ocupar.

Em segundo lugar, é notório que os revolucionários nortistas reconheciam em Távora um papel militar e político sem igual nos primeiros momentos do Governo Provisório. A ampla difusão e a força do movimento pelo generalato deram-se devido ao conturbado momento político e militar do imediato pós-30. Isso porque os "períodos de intermitência da legitimidade" são férteis aos "apelos mais veementes à intervenção do herói salvador". Ou seja, para os revolucionários nortistas, e para muitos outros entusiastas da Revolução de 30 pelo país afora, Juarez Távora era um verdadeiro herói militar, um arquétipo de "Alexandre". Por meio de sua "espada", sua legitimidade é baseada "no brilho de sua ação imediata" que mais leva à "aventura" da transformação do que "protege". ${ }^{33}$ Por isso, são fartamente utilizadas pelos articuladores do movimento palavras como sagração, evangelho, herói, prestígio, glória. Juarez, consagrado herói militar, fundaria um novo amanhã e, com isso,

\footnotetext{
${ }^{32}$ BURKE, Peter. A história dos acontecimentos e o renascimento da narrativa. In: BURKE, Peter (Org.). $A$ Escrita da história: novas perspectivas. São Paulo: Ed. Unesp, 1992, p. 73-183.

${ }^{33}$ GIRARDET, Raoul. Mitos e mitologias políticas. São Paulo: Companhia das Letras, 1987, p. 75-89.
} 
guiaria para um novo momento político o Governo Provisório e o Norte. A região tinha um "mito" que a estabelecia e a encarnava no jogo político. ${ }^{34}$

Por fim, no "campo de possibilidades" aberto com a derrubada da Primeira República, a corrente política dos revolucionários nortistas articulou um "projeto" em torno de Juarez Távora, sendo o generalato, nesse processo, estratégico. Contudo, como mostrava a reação de Távora, nesse projeto havia divergências e era vivido "de modo heterogêneo pelos indivíduos que o compartilham". ${ }^{35}$ Não que Juarez se recusasse a liderar os revolucionários nortistas, mas, para ele, a rápida promoção ao generalato poderia trazer mais embaraços do que benesses. De toda forma, mesmo com divergências na estratégia, o projeto dos revolucionários nortistas mostrava-se forte nacionalmente e chamava a atenção, fortalecendo Juarez Távora como uma das mais significativas lideranças militares de um Exército nacional em reestruturação no imediato pós-30.

\title{
De general a major: o Norte como projeto, o governo provisório como caminho
}

Dois dias depois do enorme movimento pelo generalato, Vargas escreveu a todos os interventores do Norte, justificando não ter dado a promoção de Juarez:

\begin{abstract}
Tenho recebido de vários núcleos de população desse estado, expressando movimento que se generalizou, solicitações em prol da promoção de Juarez Távora a general. Desejo que leve ao conhecimento de todos que compartilham desse movimento patriótico, que ninguém, tanto quanto eu, teria prazer em atender às aspirações da população do Norte, investindo Juarez Távora generalato, pois ele foi um dos mais notáveis generais da Revolução. Mas o capitão Juarez Távora recusa aceitar qualquer posto que não seja adquirido normalmente, e satisfeitos os vários requisitos regulamentares, em perfeita igualdade com os seus camaradas de classe. Essa nobre modéstia e desinteresse - demonstração da superioridade do seu espírito - ainda dá mais realce ao seu nome e à valia dos seus serviços. ${ }^{36}$
\end{abstract}

Ao utilizar bem as palavras para imputar ao próprio Távora a recusa, o presidente procurava não se indispor com aliados tão importantes na consolidação de seu ainda tão incerto governo. O generalato de Juarez era, de fato, um movimento amplo que significava uma articulada pressão política sobre Vargas, realizada por vários revolucionários nortistas, com apoio de parte da população e de militares estaduais, tendo em vista o fortalecimento do

\footnotetext{
${ }^{34}$ Sobre essa questão, as reflexões de Cláudia Viscardi são bastante pertinentes: "Através do trabalho de Girardet pudemos perceber como os mitos franceses, por ele trabalhados, podem ser transpostos para a realidade brasileira em diferentes períodos históricos. Novos mitos construídos, próprios à realidade política brasileira, fundamentados, inclusive, em base regionais, podem ser descobertos, com o objetivo de servirem como instrumentos explicativos de variados comportamentos políticos recorrentes". VISCARDI, Cláudia Maria Ribeiro. História, Região e... Op. cit., p. 97.

35 VELHO, Gilberto. Projeto e Metamorfose: antropologia das sociedades complexas. Rio de Janeiro: Zahar, 1999, p. 31-48.

${ }^{36}$ FGV-RJ. CPDOC, Arquivo Juarez Távora, dpf 1930.12.30 (62-63/116). Datado de 16 de janeiro de 1931.
} 
líder e dos liderados. Assim, se para Juraci Magalhães a modéstia de Juarez era "descabida", para Vargas, ela era "nobre", além de muito conveniente.

No entanto, a fala do presidente não encerrava o caso. A imprensa nortista continuou se referindo a Távora como general, preservando a narrativa de um grande herói sempre que o noticiava. Mesmo que velado, pois outras iniciativas públicas pela aclamação ao generalato não ocorreram, o embate político continuava. Na correspondência privada, ele continuava aparecendo de modo mais explícito, conforme escreveu Antenor Navarro, interventor paraibano, a Juarez: "Meu pensamento é que o Norte precisava que você fosse general. [...] Nem por leve, pensei no generalato como um prêmio e sim como uma garantia para a união do Norte e assim também para a sua força. Do contrário seremos fatalmente engolidos". ${ }^{37}$ Para os revolucionários nortistas, o projeto da região ficaria comprometido e Távora perderia força caso não se tornasse general, embora Vargas afirmasse o contrário. Sua liderança era inconteste e precisa ser efetivamente consolidada nacionalmente.

Diante disso, é necessário investigar com mais profundidade os motivos dessa recusa ao generalato, a partir da ótica do próprio Juarez. Em 17 de janeiro, ainda tratando dessa questão, disse a um de seus correspondentes nortista:

Relativamente caso generalato, $[\ldots]$ quero frisar motivos porque discordo do mesmo. Primeiro minha consciência repele ideia prêmio permanente por serviços transitórios. Segundo minha promoção criaria dentro nossa classe precedente de lamentável consequência. Terceiro minha autoridade moral decresceria com esse fato ao invés de aumentar como ilusoriamente supõem meus amigos do Norte. ${ }^{38}$

Mesmo com a ampla base de apoio que tinha, Juarez recusava o generalato, reafirmando alguns pontos de quando desautorizara o movimento que o promovia. Inicialmente justificou sua atitude por encarar seus serviços à revolução como passageiros dentro de uma trajetória maior que procuraria traçar, e por isso não poderia ser condecorado permanentemente. Ele parecia reconhecer que não merecia "prêmio" por um papel tão "modesto". Em segundo lugar, afirmava seu respeito à hierarquia militar, o que sua promoção subverteria, pois daria um grande "salto" na ordem estabelecida oficialmente. No momento em que vários projetos para a reordenação militar digladiavam-se, Távora optou por seguir as normas estabelecidas por aqueles que ocupavam os altos cargos militares, como o ministro Leite de Castro, seu padrinho de casamento. Por fim, reputava sua recusa à possibilidade de decréscimo de sua autoridade moral, certamente se referindo ao fato de tornar-se general sem o curso de Estado Maior - estudos que só iniciaria depois do fim do Governo Provisório. ${ }^{39}$ Apesar de ter sido, durante grande parte da década anterior, um combativo rebelde, Távora, vitorioso em 1930, desejava se sentir novamente parte do Exército, e, para isso era necessário

37 FGV-RJ. CPDOC, Arquivo Juarez Távora, dpf 1930.12.08 (5260-5262/7455). Datado de 21 de janeiro de 1931.

${ }_{38}$ Ibidem, (5669-5670/7455). Datado de 17 de janeiro de 1931.

39 Juarez concluiu o curso em 1938, e afirma em suas memórias que ele "ia permiti-me galgar, em condições normais, o generalato do Exército". TÁVORA, Juarez. Uma vida e muitas... Op. cit., vol. 2, p. 137. 
respeitar os critérios estabelecidos. Ou seja, na leitura que fez da sua trajetória naquela conjuntura, Juarez Távora optou por ser legalista.

Aliado a esses pontos, é importante considerar também se o generalato de Juarez poderia prejudicar, de alguma maneira, sua atuação na Delegacia Militar do Norte, instituída quase que no mesmo momento em que sua promoção foi articulada. É ele próprio que sugere isso, ao dizer, no calor das discussões sobre sua promoção, a Lima Cavalcanti, interventor pernambucano, que "como capitão poderei auxiliá-los melhor talvez que como general".40 Tornar-se general, no entendimento de Távora, era afastar-se do Norte, algo que, definitivamente, não queria. Ao assumir o posto de Delegado Militar do Norte e de um militar zeloso pelas normas legais, mesmo no conturbado imediato pós-30, na ótica de Juarez, ao contrário do que temiam alguns revolucionários nortistas, o projeto não foi "engolido" nem "sacrificado", mas estabelecido a partir de outros parâmetros.

A formação do Norte como uma região geopolítica forte, coesa, de relevância no cenário nacional não foi um contínuo, mas sim um processo marcado por conflitos e estratégias, por vezes divergentes e conflituosas. A busca pelo generalato, apesar de ter sido derrotada, serviu como forte aprendizado. Ela gerou articulação, mobilização pública, laços e reconfigurações que foram utilizadas pelos revolucionários nortistas e pelo próprio Távora em outros momentos na trajetória dessa região. Como afirma Albuquerque Júnior:

Os historiadores deveriam estar atentos para as dominações, para as relações de poder, para as alianças e dissensões, para as vitórias e as derrotas, para as lutas e conflitos que levaram à instituição de um dado recorte regional, que definiram suas fronteiras, que inventaram sua paisagem, que definiram o seu habitante, que nomearam, escolheram e instituíram o que seriam as suas manifestações culturais tradicionais, seus costumes e hábitos vistos como típicos, como autênticos, como originais, como singulares e específicos. ${ }^{41}$

O projeto do generalato não foi vitorioso, mas serviu para unir os revolucionários nortistas e formatar as fronteiras de uma região que dava seus primeiros passos e atingiu seu auge na guerra civil de 1932. Outros processos que tornaram o Norte o grande aliado do Governo Provisório - em especial frente aos opositores que se aglutinavam na corrente política liderada por São Paulo - deram certo. São exemplos de estratégias vitoriosas ocorridas na região a militarização das interventorias nortistas (quando a maioria dos interventores da região foram trocados, assumindo militares), as respostas coordenadas às oposições que lideravam o processo que pressionava pela imediata constitucionalização e o combate articulado a qualquer movimento pró-São Paulo nos estados do Norte antes e durante a guerra civil. Sem contar a ação administrativa da Delegacia Militar do Norte na busca por recursos e na mediação junto ao governo federal para a resoluções de problemas estaduais. ${ }^{42}$ Em resumo, a formatação de correntes políticas marcadas pela regionalidade é complexa e não

\footnotetext{
40 FGV-RJ. CPDOC, Arquivo Juarez Távora, dpf 1930.12.08 (5667-5668/7455). Datado de 17 de janeiro de 1931.

${ }^{41}$ ALBUQUERQUE JúNIOR, Durval Muniz de. O objeto em fuga... Op. cit., p. 63-64.

42 LOPES, Raimundo Helio. Um Vice-reinado na República... Op. cit., p. 73-183.
} 
pode ser reduzida a eventos isolados ou a processos sem conflitos. Na verdade, é justamente nos embates entre seus artífices que as regiões ganham forma.

$\mathrm{Na}$ defesa de um projeto para a região que liderava, Távora não assumiu um posto militar de grande patamar efetivo, pelo comando, e simbólico, pelo modo de ascensão. Foi reconhecido - e reconhecia-se - como o grande líder dos revolucionários nortistas e, mesmo sem ser general, foi o responsável pela contínua construção e manutenção da aliança política do Norte com o Governo Provisório. Essa aliança foi fundamental para a vitória de Vargas na guerra civil de 1932.

Como não chegou ao generalato em janeiro de 1931, em março do mesmo ano, Juarez foi promovido a major, o posto coerente com hierarquia estabelecida, mas bem menor do que aquele pretendido por seus aliados. No Norte, esta promoção foi recebida com frieza. A maioria dos jornais apenas noticiou o fato, sem maiores comentários ou lamentações. Rara exceção foi o Jornal Pequeno de Recife, ao dizer que o "Norte, que o tem como seu intemerato defensor, o fiador do seu progresso, o responsável pelos seus destinos republicanos, não pode deixar de receber com alegria a notícia de sua promoção". ${ }^{43} \mathrm{O}$ movimento que buscava o generalato de Juarez Távora terminava, sem êxito. Mas, a liderança de Juarez no Norte junto ao Governo Provisório continuaria, até o final da Assembleia Constituinte de 1934.

Um arguto analista político captou essa situação. Aparício Torelly, o Barão de Itararé, em seu cômico e crítico jornal $A$ Manha, sintetizou de modo exemplar a promoção de Juarez ao posto de major, ao contrário das expectativas pelo generalato:

O sr. capitão-general Juarez Távora acaba de ter um gesto de rara abnegação, recusando peremptoriamente a sua promoção ao posto de major. Justificando plenamente essa recusa, $[. .$.$] Juarez Távora explica que prefere marcar passo$ no posto de capitão, para poder continuar administrando as "capitanias" do Norte. Promovido a major já não poderia prosseguir nessa louvável tarefa, a não ser que as "capitanias" fossem também promovidas a "majorias", o que acha pouco provável. ${ }^{44}$

A "abnegação", sinônimo para modéstia, voltou através da pena irônica do Barão de Itararé. A atuação ao lado das interventorias nortistas, o respeito pelas normas militares de um Exército em reconstrução, e o reconhecimento da autoridade de outros líderes, como Leite de Castro e Getúlio Vargas, são as motivações para que Juarez Távora não tenha se empenhado pela sua promoção a general. O projeto que ele construía para o Norte - com contradições, conflitos e transformações que respondiam à instabilidade política que vivenciavam naquela conjuntura - tinha à fidelidade ao Governo Provisório como caminho. Nas incertezas do imediato pós-30, ele deixou de ser um potencial competidor - já que se tornaria general de modo política e militarmente inédito na história nacional - para tornar-se um fiel aliado, respeitando normas e hierarquias.

\footnotetext{
43 Juarez Távora - o valoroso chefe revolucionário do norte foi promovido a major. Jornal Pequeno, Recife, 14 abr. 1931, p. 1.

${ }^{44}$ Recusando a promoção - o general Juarez Távora prefere continuar como capitão. A Manhã, Rio de Janeiro, 13 mar. 1931 , p. 2.
} 
O movimento pelo generalato de Juarez Távora deixa antever que o Governo Provisório não pode ser compreendido sem se considerar que muitos projetos, correntes, identidades, regiões surgiram naquele momento. Alguns foram mais longevos, outros, curtos e intensos. Mas, mesmo que derrotados e esquecidos, tais iniciativas, múltiplas e diversas, não podem ser minimizadas. Ainda é preciso entender bem mais sobre elas, a partir de suas próprias trajetórias e articulações, desnaturalizando, assim, muitas de suas "fronteiras". 


\section{Referências}

\section{Fontes}

\section{Arquivos Pessoais}

Fundação Getúlio Vargas - Rio de Janeiro. Centro de Pesquisa e Documentação de História Contemporânea do Brasil (CPDOC), Arquivo Juarez Távora, dpf 1930.12.08; dpf 1930.12.30; dpf 1946.06.24.

\section{Periódicos}

Aviso! Diário de Pernambuco, Recife, 13 jan. 1931.

Importantes decretos na pasta da Guerra. Correio da Manhã, Rio de Janeiro, 9 nov. 1930.

Instituto Arqueológico. Diário de Pernambuco, Recife, 13 jan. 1931.

Juarez Távora - o grande comício popular de ontem em prol da elevação do intrépido chefe revolucionário do norte ao generalato do exército nacional. Diário de Pernambuco, Recife, 15 jan. 1931.

Juarez Távora - o grande plebiscito que se realizará hoje em todo o norte do país em prol do generalato para o bravo soldado republicano. Diário de Pernambuco, Recife, 14 jan. 1931.

Juarez Távora - o valoroso chefe revolucionário do norte foi promovido a major. Jornal Pequeno, Recife, 14 abr. 1931.

Juarez Távora, general da vitória e do Exército Brasileiro - A imponente cerimônia cívica de ontem. Jornal Pequeno, Recife, 15 jan. 1931.

Juarez Távora, general da vitória e do Exército Brasileiro - O formidável plebiscito do dia 14 em todo o norte do Brasil, da Bahia ao Amazonas. Jornal Pequeno, Recife, 9 jan. 1931.

Juarez Távora, general da vitória e do Exército Brasileiro - O grande plebiscito de hoje, na Praça Barão de Lucena. Jornal Pequeno, Recife, 14 jan. 1931.

Juarez Távora. Diário de Pernambuco, Recife, 10 jan. 1931.

Juarez Távora. Jornal do Recife, Recife, 15 jan. 1931.

Novo general. Jornal do Recife, Recife, 14 jan. 1931.

Recusando a promoção - o general Juarez Távora prefere continuar como capitão. A Manha, Rio de Janeiro, 13 mar. 1931.

Uma expressiva homenagem dos colegas de turma do senhor Osvaldo Aranha. Correio da Manhã, Rio de Janeiro, 28 dez. 1930.

\section{Bibliografia}

ALBUQUERQUE JUNIOR, Durval Muniz de. A invenção do nordeste e outras artes. São Paulo: Cortez, 2009. 
ALBUQUERQUE JUNIOR, Durval Muniz de. O objeto em fuga: algumas reflexões em torno do conceito de região. Fronteiras, Dourados (MS), v. 10, p. 55-67, jan.-jun. 2008.

BURKE, Peter. A história dos acontecimentos e o renascimento da narrativa. In: BURKE, Peter (Org.). A Escrita da história: novas perspectivas. São Paulo: Ed. Unesp, 1992.

CARVALHO, José Murilo de. Forças Armadas e política no Brasil. São Paulo: Todavia, 2019.

GARCIA JÚNIOR, Afrânio. Os Vice-Reis do Norte: reconversão de elites agrárias e a revolução de 1930 (1920-1964). Revista de Ciências Sociais, Fortaleza, v. 38, n. 2, p. 73-87, 2007.

GIRARDET, Raoul. Mitos e mitologias políticas. São Paulo: Companhia das Letras, 1987.

KOSELLECK, Reinhart. Futuro Passado: contribuição à semântica dos tempos históricos. Rio de Janeiro: Contraponto; Ed. PUC-Rio, 2006.

LOPES, Raimundo Helio. Um Vice-reinado na República do pós-30: Juarez Távora, as interventorias do Norte e a Guerra de 1932. 2014. Tese (Doutorado em História, Políticas e Bens Culturais) - Centro de Pesquisa e Documentação de História Contemporânea do Brasil, Fundação Getúlio Vargas, Rio de Janeiro.

LOPES, Raimundo Helio. O Vice-Rei do Norte: Juarez Távora entre inimigos e aliados. Revista Tempo, Niterói (RJ), IH/UFF, v. 23, p. 139-158, 2017.

MCCANN, Frank D. Soldados da Pátria: história do exército brasileiro, 1889-1937. São Paulo: Companhia das Letras, 2007.

MOTTA, Rodrigo Patto Sá. Batalhas em torno do mito: Luiz Carlos Prestes. Estudos Históricos, Rio de Janeiro, n. 34, p. 91-115, 2004.

RECKZIEGEL, Ana Luiza Setti. História regional: dimensões teórico-conceituais. História debates e tendências, Passo Fundo (PR), v. 1, n. 1, p. 15-22, 1999.

TÁVORA, Juarez. Uma vida e muitas lutas - memórias. Vol. 1: Da planície à borda do Altiplano. Rio de Janeiro: José Olympio, 1973.

TÁVORA, Juarez. Uma vida e muitas lutas - memórias. Vol. 2: A caminhada no Altiplano. Rio de Janeiro: Biblioteca do Exército, 1976.

VELHO, Gilberto. Projeto e Metamorfose: antropologia das sociedades complexas. Rio de Janeiro: Zahar, 1999.

VISCARDI, Cláudia Maria Ribeiro. História, Região e Poder: a busca de interfaces metodológicas. Locus: revista de história, Juiz de Fora (MG), v. 3, n. 1, p. 84-97, 1997. 
